\title{
Os jogos eletrônicos como instrumento pedagógico nas aulas de educação física escolar
}

The electronic games as pedagogic instrument in school physical education classes

Los juegos electrónicos como instrumento pedagógico en las clases de educación física escolar

\author{
Carla Gomes Borges ${ }^{\mathrm{I}}$, Bruno Dandolini Colombo ${ }^{\mathrm{II}}$
}

\begin{abstract}
Resumo
Este artigo tem como objetivo analisar de que forma os jogos eletrônicos podem ser utilizados como instrumento pedagógico nas aulas de educação física escolar. Trata-se de uma pesquisa bibliográfica. Conclui-se que os jogos eletrônicos podem ser utilizados para abordar vários conteúdos da educação física escolar, como por exemplo, conhecimentos técnico-táticos de determinadas modalidades esportivas.
\end{abstract}

Palavras-chave: Jogos eletrônicos; ; Educação física escolar; Instrumento pedagógico

\begin{abstract}
This article aims to analyze how electronic games can be used as a pedagogical instrument in school physical education classes. This is a bibliographic research. It is concluded that electronic games can be used to address various contents of school physical education, such as technical-tactical knowledge of certain sports.
\end{abstract}

Keywords: Electronic games; School physical education; Pedagogical instrument

\footnotetext{
${ }^{\mathrm{I}}$ Universidade do Extremo Sul Catarinense - UNESC - Criciúma, SC, Brasil - e-mail: carlagomes.b@bol.com.br

II Universidade do Extremo Sul Catarinense - UNESC - Criciúma, SC, Brasil - Endereço: Rua Floresta, 32, Vila Floresta, Criciúma - SC, Brasil, CEP: 88817107 - e-mail: bruno@unesc.net
} 


\section{Resúmen}

Este artículo tiene cómo objetivo analizar de qué forma lós juegos electrónicos pueden ser utilizados como instrumento pedagógico en las clases de educación física escolar. Se trata de una investigación bibliográfica. Se concluye que los juegos electrónicos pueden ser utilizados para abordar varios contenidos de la educación física escolar, cómo por ejemplo, conocimientos técnico-tácticos de determinadas modalidades deportivas.

Palavras clave: Juegos electrónicos; Educación física escolar; Instrumento Pedagógico

\section{Introdução}

$\mathrm{Na}$ atualidade os jogos eletrônicos ${ }^{1}$ estão presentes na vida dos sujeitos, principalmente na vida dos jovens e das crianças. Com o passar dos anos esta tecnologia vem avançando, aprimorando e evoluindo, sendo que muitas crianças e jovens têm ou tiveram contato com algum tipo de jogo eletrônico, sendo na sua casa, ou nas dos amigos, até mesmo em lan house $e^{2}$.

Os jogos eletrônicos efetivam-se em vídeo games, computadores e nos últimos anos em celulares.

Vivemos numa sociedade em que o acesso à mídia eletrônica (televisão, celulares, computadores, videogames, internet, etc.) e, em especial, aos jogos eletrônicos, tem crescido vertiginosamente. Estes jogos representam não só o que há de mais moderno e inovador em matéria de diversão eletrônica, mas também aparentam ser uma das expressões culturais do processo de mundialização. Os jogos eletrônicos são um dos objetos mais consumidos no mundo inteiro, ultrapassando 2,8 milhões de produtos comercializados apenas em nosso país. (MENDES, 2005, p.15).

Diante disso, acreditamos ser fundamental pesquisas que reflitam acerca do fenômeno jogos eletrônicos e, mais ainda, relacione-o com o processo educativo. Assim, temos o seguinte tema de pesquisa: Os jogos eletrônicos como instrumento pedagógico nas aulas de educação física escolar, desdobrando-se no seguinte problema de pesquisa: De que forma utilizar os jogos eletrônicos como ferramenta pedagógica nas aulas de educação física escolar? O intuito da pesquisa é pensar e refletir que o jogo eletrônico pode ser mais do que uma atividade de lazer, sendo, também, uma nova ferramenta pedagógica de ensino utilizada pelo professor em suas aulas.

Para que possamos esclarecer melhor nosso propósito, elencamos algumas questões norteadoras:

A). Os jogos eletrônicos são relevantes nas aulas de educação física escolar nos dias de hoje?

\footnotetext{
${ }^{1}$ Neste artigo utilizaremos jogos eletrônicos como sendo os jogos em que o jogador interage com imagens enviadas a um dispositivo que as exibem, geralmente uma televisão ou um monitor.

${ }^{2}$ Lan Hause é um estabelecimento comercial onde os usuários pagam para utilizar um computador com acesso à Internet, com o principal fim de acesso à informação rápida pela rede e entretenimento através dos jogos em rede ou online.
} 
B). Qual a relação que a educação física tem com os jogos eletrônicos?

Temos como objetivo refletir acerca dos jogos eletrônicos como ferramenta pedagógica na organização do ensino das aulas de educação física escolar.

Para responder ao problema e objetivo apontado foi realizado uma pesquisa bibliográfica.

A pesquisa bibliográfica [...] é feita a partir do levantamento de referências teóricas já analisadas, e publicadas por meios escritos e eletrônicos, como livros, artigos científicos, páginas de web sites. Qualquer trabalho científico inicia-se com uma pesquisa bibliográfica, que permite ao pesquisador conhecer o que já se estudou sobre o assunto. Existem, porém pesquisas científicas que se baseiam unicamente na pesquisa bibliográfica, procurando referências teóricas publicadas com o objetivo de recolher informações ou conhecimentos prévios sobre o problema a respeito do qual se procura a resposta. (FONSECA, 2002, p.32)

Sendo assim, nos referendamos em artigos científicos, livros e sites, para que o presente artigo fosse construído.

\section{Jogos Eletrônicos}

Segundo Amorin (2006) os primeiros jogos eletrônicos surgiram na década de 70 e 80, originando-se em Massachusetts, nos Estados Unidos. A partir daí estes tipos de jogos começaram a ser populares e atrativos entre as crianças e os jovens. Desde então, vêm se tornando mais popular e tecnológico, com jogos, gráficos e imagens que imitam a realidade.

Segundo a Associação Brasileira das Desenvolvedoras de Jogos Eletrônicos (ABRAGAMES), o Brasil corresponde a $0,16 \%$ do faturamento mundial de jogos eletrônicos, e passa por um período forte de expansão e conquista de novos mercados. Expansão esta que é fortemente influenciada pelo crescimento acelerado de games no mundo.

\footnotetext{
Atualmente os jogos eletrônicos são atrativos para nossas crianças porque combinam diversas linguagens, o ambiente virtual e multimídia, a qual combina imagens, sons e textos, incluindo os minis games, os jogos para computador (em rede ou não), os softwares para videogames, os simuladores e os fliperamas e se constituem como artefatos de grande fascínio econômico, tecnológico e social. Os jogos eletrônicos atingem desta forma, um número maior de usuários, já que normalmente são prazerosos e dinâmicos, despertando curiosidade, interesse e estimula a aprendizagem cognitiva, afetiva e social de um modo divertido, tanto o jogo em si como os jogos eletrônicos. (GUMZ; VAZ; LEAL, 2014, p.7).
} 
O que torna o jogo mais atrativo são as combinações de linguagem que abrange todas as faixas etárias. Outra questão é o fato do jogo trazer contribuições ao desenvolvimento da criatividade, da concentração, trazendo ao aluno formas de vivenciar as técnicas e as táticas, ajudando o aluno a tomar decisões e até mesmo refletir sobre.

O jogo é uma maneira de imitar situações reais ou fictícias, permitindo ao homem fazer descobertas, desenvolver sua criatividade, ir ao encontro do eu e do outro e renovar sua energia. Por meio do jogo se aprende a agir, estimulando a curiosidade, a iniciativa e autoconfiança, ao mesmo tempo em que o desenvolvimento da linguagem, do pensamento e da concentração é proporcionado. Os jogos podem, portanto, desenvolver as capacidades intelectuais do jogador. (SANTOS, 2008, p.18).

Pensando no contexto escolar, principalmente, nas aulas de educação física, os jogos eletrônicos podem ser um componente importante, pois por meio dos jogos eletrônicos os alunos podem se apropriar de um determinado conhecimento. Sendo vital que o professor intermedeie as aulas para que o jogo não seja jogado somente por jogar, mas que o aluno aprenda com o jogo. Mesmo porque

O jogo satisfaz necessidades das crianças, especialmente necessidade de "ação". Para entender o avanço da criança no seu desenvolvimento, o professor deve conhecer quais as motivações, tendências e incentivos que a colocam em ação. Não sendo o jogo aspecto dominante da consciência, ele deve ser entendido como "fator de desenvolvimento" por estimular a criança no exercício do pensamento, que pode desvincular-se das situações reais e levá-la a agir independentemente do que ela vê. (COLETIVO DE AUTORES 1992, p, 45)

Assim, o professor de educação física precisa organizar o ensino de forma que promova o desenvolvimento de seus alunos. Além do domínio do próprio jogo eletrônico, há jogos que contribuem para que o aluno aprenda as regras e as táticas de outros jogos, principalmente os jogos esportivos. Em nível de exemplo, destaca-se o Brasfoot.

$\mathrm{O} \mathrm{JE}^{3}$ Brasfoot é um game de futebol que guarda a correlação dos três aspectos característicos de um JE. Ao se "entregar" a tal simulador, o jogador se depara com o dualismo imaginação realidade: ao viver como administrador/técnico de um time de futebol o sujeito-jogador expõe suas expectativas sobre ser um "profissional do futebol", e se apropria de alguns saberes reais inerentes aos bastidores de um clube oficial de futebol. (MORAIS E MENDES, 2013, p.216).

Através do jogo é possível entender parte da realidade do futebol. Por meio do JE você pode ser um jogador, um técnico ou um empresário. Ainda sobre o Brasfoot os autores destacam que:

As possibilidades que este game traz, como, por exemplo, comprar e vender jogadores, construir estádios, alterar preços de ingressos de camarotes, cadeiras e geral, convocar jogadores para competições internacionais de seleções, ser convocado como técnico por outros times, escolher a formação do time, os reservas, a cor de uniforme, acumular troféus, dentre outras, fazem com que a ação executada no hardware possa ser efetivada na simulação para a conclusão das escolhas que podem levar ao fracasso do clube ou sua ascensão - que darão a oportunidade de iniciar outro jogo, novas compras, etc, e permitirá ao usuário intervir a seu próprio modo para alcançar um resultado positivo. (MORAIS E MENDES, 2013, p.216).

\footnotetext{
${ }^{3}$ JE sigla para Jogos Eletrônicos.
} 
Além do mais, os jogos que os alunos irão jogar também devem ser aprovados pelo professor de educação física, para que os alunos não joguem qualquer jogo. Os professores também devem estar preparados para utilizar esta nova ferramenta. Para Azevedo, Pires e Silva (2007) existem limites nas formações continuadas e iniciais de professores. Estas não tratam os jogos eletrônicos como ferramenta pedagógica. Outro limite apontado pelos autores é o cerceamento na estrutura das escolas. Estas apresentam, muitas vezes, insuficientes recursos tecnológicos para a realização dos jogos eletrônicos enquanto conteúdo.

Não basta ter esta ferramenta pedagógica disponível na escola e os professores não estarem aptos a utilizarem de maneira correta, nem terem formação para tal e não obterem condição objetiva para utilizá-la.

Para Ramos (2008) o professor tem uma função estratégica quando pensamos na aplicabilidade pedagógica dos jogos eletrônicos e nos reflexos que eles podem ter no desenvolvimento humano.

\section{A educação física e a relação com os jogos eletrônicos}

Vimos que hoje em dia os jogos estão presentes em vários espaços. Não seria diferente nas aulas de educação física escolar.

Se cabe à Educação Física introduzir e integrar o aluno na cultura corporal de movimento há que se considerar que: I) a integração há de ser do aluno, concebido como uma totalidade humana, com suas dimensões físico-motora, afetiva, social e cognitiva, e II) o consumo de informações e imagens provenientes das mídias faz parte da cultura corporal de movimento contemporânea, e, portanto, não pode ser ignorada; pelo contrário, deve ser objeto e meio de educação, visando instrumentalizar o aluno para manter uma relação crítica e criativa com as mídias" (BETTI, 2003, p. 97-8).

De acordo com Azevedo, Pires e Silva (2007, p. 4) "Os jogos eletrônicos veiculam diversos valores e podem desenvolver várias habilidades e conhecimentos em seus jogadores, podendo ser utilizados como proposta educativa com a mediação dos professores nas escolas". Portanto isso precisa ser tematizado e problematizado na educação física escola.

É hora de a educação física escolar dar um passo de maior qualidade em sua prática pedagógica, oferecendo aos alunos oportunidades de contato com outras linguagens e outras formas de cultura, associando-as com as 'velhas' e 'novas' práticas da cultura corporal de movimento e trabalhando o conhecimento daquela forma de cultura também pelo compreender, sentir e relacionar-se. É preciso, enfim, superar o velho chavão da aula prática. (BATISTA E BETTI 2005, p. 146). 
Muitos ainda identificam os jogos eletrônicos como algo ruim e que não se adequa ao ambiente escolar. Lógico como tudo o que se faz exageradamente e sem o acompanhamento pode não ser bom, no entanto, o lado bom dele vem sendo exaltado nas últimas décadas, principalmente após vários estudos psicopedagógicos que retrataram a importância do jogo no desenvolvimento infantil. (ABREU, 2003)

De acordo com Magagnin (2009) os jogos eletrônicos nas escolas devem ter o intuito de desenvolver a aprendizagem, e construir habilidades. Neste sentido os jogos eletrônicos configuram-se como aliado para as aulas de educação física.

É papel do professor se aproximar desta realidade, pois, a escola precisa saber sobre o cotidiano de seus alunos, e aproveitar esse cotidiano para poder desenvolver o ensino por meio deste meio educativo. A escola, além disto, deve proporcionar suporte para que o aluno desenvolva todas suas capacidades e auxiliar com as existentes incapacidades. (MAGAGNIN, 2009)

Como os jogos tradicionais são utilizados de diversas formas, principalmente voltada mais para o lúdico, a movimentação corporal, os jogos virtuais também vêm sendo utilizados como artefatos de formação do ensinoaprendizagem. Quando a criança joga algum tipo de jogo eletrônico, ela precisa desenvolver algumas técnicas de raciocínio rápido. Existem jogos que demandam uma precisão de agilidade, coordenação motora. Alguns jogos possibilitam os aspectos sociais, características que a educação física escolar trabalha nas escolas. (SOUZA E MAGALHÃES, 2008)

Os jogos eletrônicos são recursos inovadores de espaço da sala de aula, podendo ser utilizada como uma forma de motivação dos alunos, tendo um alto poder de ilustração. Constitui-se como um instrumento educacional que oportuniza diferentes experiências ao aluno. Permite, também, a análise de situações simuladas, o respeito ao ritmo de aprendizagem dos alunos, a inclusão de pessoas deficientes em tarefas diversas, e estimula a participação ativa dos alunos nas aulas. (BRAGA, 2001)

Mesmo assim, ainda se vê os jogos eletrônicos com maus olhos, pois não é uma ferramenta muito utilizada. Precisamos quebrar esse paradigma de que os jogos eletrônicos é necessariamente algo ruim.

Muito ainda precisa ser estudado na relação da criança com o videogame. Existem uma série de aspectos que precisam ser analisados detalhadamente, como os psicológicos, os educativos e os fatores da comunicação. Também é preciso que haja menos preconceito em relação aos games por parte de pais, educadores e pesquisadores. Muitas críticas negativas dos jogos afirmam a questão da manipulação, imperialismo e globalização. Entretanto, algumas delas são baseadas no senso comum, sem apresentar argumentos sólidos ou mesmo de levantamentos empíricos. (KRUGER E CRUZ, 2001, p. 15).

A reflexão sobre os jogos eletrônicos na Educação Física escolar faz parte de uma discussão maior que diz respeito ao ensino e ao uso de diferentes linguagens no cotidiano dessa disciplina. (SILVEIRA E TORRES, 2007 p. 7) 
Costa e Betti (2006) afirmam que a Educação Física deve se apropriar de diversas formas de vivências, fazendo oscilar os processos de virtualização e atualização.

\begin{abstract}
Assistir, praticar, jogar vídeo games, falar sobre os jogos, as aventuras e as lutas dos personagens de desenhos, filmes e jogos eletrônicos, brincar e fantasiar com eles e sobre eles, todas essas experiências são constituintes e constituidoras da cultura lúdica infantil e devem ser apropriadas de modo crítico pela Educação Física na escola, se essa disciplina, por sua vez, quiser atualizar a sua prática pedagógica, e não ficar alheia ao seu tempo. (COSTA E BETTI, 2006, p. 176).
\end{abstract}

Os jogos eletrônicos que representam os esportes são tanto um universo de estudo que possui suas próprias regras de funcionamento quanto uma possibilidade lúdica de aprendizagem sobre o universo do esporte. Podendo assim ser tratado em outros temas da Educação Física (jogos, danças, lutas, ginásticas, capoeira), que também aparecem no mundo virtual. Enfim, entendemos que é urgente a aproximação da Educação Física escolar a essa dimensão da cultura lúdica, de forma que não se negue aos alunos a oportunidade de construir uma compreensão e uma prática crítica sobre a mesma. (SILVEIRA E TORRES 2007 p,8).

Batista e Betti (2005) afirmam que a necessidade de educar os alunos e a população para a cultura eletrônica, assim como outras formas culturais, indica que a escola precisa ensinar a refletir sobre os jogos eletrônicos, tornando imperativa sua seleção como conteúdo da Educação Física escolar.

\title{
4 CONSIDERAÇÕES FINAIS
}

Conforme podemos ver ao decorrer de nossa pesquisa, os jogos eletrônicos vêm em uma grande crescente desde sua criação na década de 70 . A cada ano que se passa ele vem evoluindo.

Um fenômeno que atrai os jovens até os dias de hoje. Desta forma, fica a pergunta: de que forma utilizarmos os jogos eletrônicos nas escolas?

Utilizando os jogos eletrônicos como uma ferramenta pedagógica; podendo usar os jogos eletrônicos para abordar vários conteúdos da educação física escolar; trazendo para a sala de aula outra forma de o aluno pensar criticamente; fazendo com que o aluno e o professor possam discutir as características e os valores vinculados aos jogos, como os diversos gêneros dos jogos, e as suas diversas formas de serem jogados.

Para Libânio (1985, p.39) "não basta que os conteúdos sejam apenas ensinados, ainda que bem ensinados é preciso que se liguem de forma indissociável a sua significação humana e social”". 
A utilização dos jogos eletrônicos como ferramenta pedagógica, traz para o aluno algo moderno, e que Segundo Coletivo de Autores (1992, p.19) a contemporaneidade do conteúdo deve garantir aos alunos o conhecimento do que há de mais moderno que existe no mundo contemporâneo.

Sabemos também que o professor deve estar preparado para dialogar com os alunos que estão integrados a essa tecnologia, não somente os professores, mas também as escolas devem estar preparadas para receber esta nova ferramenta pedagógica. Mais do que isso. Sabemos que nem todas as escolas estão aptas a receber esta ferramenta pedagógica. Portanto, destacamos que se deve haver mais investimentos nas estruturas escolares e nas formações de seus professores, para que qualquer nova ferramenta pedagógica que surgir possa ser inserida na escola sem nenhum obstáculo e que os alunos possam ter uma educação de qualidade nas escolas.

\section{Referências}

ABREU, A. Um bem ou um mau: um breve panorama da influência dos jogos eletrônicos na cultura individual e coletiva. São Paulo, 2003. Disponível em: www.andreabreu.com.br. Acesso em: 19 mai. 2018.

AMORIN, A. A origem dos jogos eletrônicos. São Paulo: USP, 2006.

ASSOCIAÇÃO BRASILEIRA DE DESENVOLVEDORAS DE JOGOS ELETRÕNICOS (ABRAGAMES). Disponível em: http://www.abragames.org. Acesso em: 28 mai. 2018

AZEVEDO, V. A. Pires, G. L. Silva, A. P. S. Jogos Eletrônicos e Suas Possibilidades Educativas. Motrivivência, Florianópolis, $\quad$ n. $28,2007.2$ Disponível https://periodicos.ufsc.br/index.php/motrivivencia/article/view/9741/9490 Acesso em: 27 mai. 2018.

BATISTA, S. R.; BETTI, M. A televisão e o ensino da educação física na escola: uma proposta de intervenção. Revista Brasileira de Ciências do Esporte, Campinas, v. 26, n. 2, p.135-148, jan. 2005.

BETTI, M. A Janela de Vidro. Campinas: Papirus, 1998.

BRAGA, M. Realidade virtual e educação. Revista de Biologia e Ciências da Terra, Paraíba, v. 1, n. 1, jan./jun. 2001.

COLETIVO DE AUTORES. Metodologia do ensino de educação física. São Paulo: Cortez, 1992.

FONSECA, J. J. S. Metodologia da pesquisa científica. Fortaleza: UECE, 2002.

GUMZ, A. C. R.; VAZ, C. S.; LEAL, V. H. Ensinando Através dos Jogos. In: IV Congresso de Letras. Caderno de Resumos. Curitiba, PR: FARESC, 2014. Disponível em: http://www.santacruz.br/v4/download/caderno-deresumos/2014/ensinando-atraves-dos-jogos.pdf. Acesso em: 10 mai. 2019.

KRUGER, F. L.; CRUZ, D. M. Os Jogos Eletrônicos de Simulação e a Criança. In: XXIV Congresso Brasileiro de Ciências da Comunicação, 2001, Campo Grande. Anais [...]. Disponível em: http://reposcom.portcom.intercom.org.br/bitstream/1904/4711/1/NP8KRUGER.pdf. Acesso em: 29 mai. 2018

LIBÂNEO, J. C. Didática. São Paulo: Cortez, 1991. 
LIBÂNEO, J. C. Democratização da escola pública: a pedagogia crítico-social dos conteúdos. São Paulo: Loyola, 1985.

MAGAGNIN, C. D. M.; MIRZA, S. T. Aprendizagem escolar: os jogos eletrônicos na formação do aluno. Disponível em: https://anaisdosimposio.fe.ufg.br/up/248/o/1.4._52_.pdf. Acesso em: 28 abr. 2018.

MASCHIO, V; RIBAS, J. F. M. O jogo Enquanto Conteúdo da Educação Física Escolar na Abordagem Critico Superadora. Santa Maria, 2009. Disponível em: http://repositorio.ufsm.br/bitstream/handle/1/2846/Maschio Vanderleia.pdf?sequence=1 Acesso em: 27 mai. 2018.

MENDES, C. L. Jogar jogos eletrônicos: que lazer é esse? Licere. Belo Horizonte, v. 8, n. 1, 2005.

MORAIS, R. A. R.; MENDES, D. de S. O esporte-simulação: O que é possível aprender com os jogos eletrônicos? Atos de Pesquisa em Educação. v. 8, n. 1, p. 209-238, jan./abr., 2013.

RAMOS, D. K. A escola frente ao fenômeno dos jogos eletrônicos: aspectos morais e éticos. Revista Novas Tecnologias na Educação, Porto Alegre, v. 6, n. 1, jul. 2008.

SANTOS, N. Espaços virtuais de ensino aprendizagem. São Paulo: Infolink, 2008.

SILVEIRA, G. C F.; TORRES, L. M. Z. B. Educação Física Escola: um olhar sobre os jogos eletrônicos. Disponível em: http://www.cbce.org.br/docs/cd/resumos/157.pdf. Acesso em: 29 mai. 2018.

SOUZA, I. R. L.; MAGALHÃES, H. P. Intersecções entre culturas midiáticas e cibercultura e game cultura. Revista Cultura Midiática, ano 1, n. 1, jul./dez. 2008.

\section{Como citar este artigo}

BORGES, Carla Gomes; COLOMBO, Bruno Dandolini. Os jogos eletrônicos como instrumento pedagógico nas aulas de educação física escolar. Revista Kinesis, Santa Maria, v. 37, p. 01-09, 2019. 